\title{
Primary modulation by oestradiol of the production of an oviduct-specific glycoprotein by the epithelial cells in the oviduct of newborn golden hamsters
}

\author{
H. Abe, T. Satoh and H. Hoshi \\ Research Institute for the Functional Peptides, Shimojo, Yamagata 990, Japan
}

\begin{abstract}
The effects of steroid hormones (oestradiol and progesterone) on the appearance of a golden hamster oviduct-specific glycoprotein (GHOGP) in the epithelium of the oviduct of the newborn golden hamster were investigated by immunoblotting and immunohistochemical staining with a GHOGP-specific monoclonal antibody. Newborn golden hamsters (1.5 days old) were injected daily with oestradiol $(1 \mu \mathrm{g})$ or progesterone $(10 \mu \mathrm{g})$. An oviductal extract of oestradiol-treated golden hamsters for 4 days apparently immunoreacted with the monoclonal antibody on a broad band with a molecular mass of more than $200 \mathrm{kDa}$ by immunoblotting under reducing conditions. This broad band was consistent with the migration of GHOGP in an extract of adult oviducts. Consecutive daily injections of oestradiol induced the appearance of GHOGP in undifferentiated epithelial cells of the oviduct of neonates. In oviducts of oestradiol-injected animals, GHOGP was first detected in the Golgi region and then increased in amount to fill the supranuclear cytoplasm of the epithelial cells. The inductive effect of oestradiol was dose-dependent. In contrast, consecutive daily injections of progesterone had no effect on the appearance of GHOGP in the oviductal epithelium. The effects of oestradiol and progesterone in organ culture of oviducts were examined in vitro, by culturing oviductal organs from 1.5-day-old newborn golden hamsters in chemically defined medium supplemented with oestradiol or progesterone for 2 days and then subjected to immunohistochemical staining. The immunoreaction was detected only in the epithelial cells of oestradiol-treated oviducts at concentrations of $>0.01 \mathrm{ng} \mathrm{ml}^{-1}$, but not in the cells of untreated and progesterone-treated oviducts. These results indicate that the production of GHOGP in the epithelial cells of the oviduct of newborn golden hamsters is induced by oestradiol both in vivo and in vitro. It is suggested that oestradiol may be involved in the synthesis of GHOGP in the oviduct during postnatal development of golden hamsters.
\end{abstract}

\section{Introduction}

The mammalian oviduct is a tubular conduit that is the site of extremely important processes, including the final maturation of male gametes, fertilization, and the early development of embryos. The nonciliated secretory cells of the mammalian oviduct produce and secrete oviduct-specific glycoproteins (OGPs) that may regulate or be involved in various reproductive events (Hunter, 1994; Malette et al., 1995a). Some of the OGPs associated with the ovulated eggs or developing embryos have been identified and characterized in several species, such as mice (Kapur and Johnson, 1985), golden hamsters (Leveille et al., 1987), pigs (Buhi et al., 1993), goats (Abe et al., 1995a), cows (Boice et al., 1992) and monkeys (Boice et al., 1990a). Several OGPs become associated with the surface of spermatozoa (Sutton et al., 1984; McNutt et al., 1992; Abe et al., 1995b) and may, thereby, affect fertilization and other

Received 4 June 1997 functions of spermatozoa (King et al., 1994; Boatman and Magnoni, 1995; Abe et al., 1995b; Satoh et al., 1995).

In previous studies, it was demonstrated that an oviductal glycoprotein (GHOGP) from the golden hamster is associated with the zona pellucida of ovulated eggs of golden hamsters (Oikawa et al., 1988; Abe et al., 1992). Monoclonal antibodies (mAbs) specific for this GHOGP were used to clarify the ultrastructural localization of GHOGP in the oviductal epithelium, and ultrastructural evidence was obtained for an association between GHOGP and the zona pellucida or perivitelline matrix of the golden hamster egg (Abe and Oikawa, 1990a, 1991). In sexually mature golden hamsters, GHOGP is secreted primarily by ampullary and isthmic secretory cells and then accumulated in the ovarian bursal sac. These observations suggest regional differences in the production of GHOGP by epithelial cells (Abe and Oikawa, 1991). However, the critical functions of the GHOGP remain to be determined.

A recent study showed that consecutive injections of oestradiol induced the cytodifferentiation of the secretory cells 
in the oviduct of newborn golden hamsters, whereas injections of progesterone significantly enhanced the rate of appearance of ciliated cells but not of secretory cells (Abe and Oikawa, 1993). These findings suggest that the cytodifferentiation of epithelial cells in the oviduct of newborn golden hamsters is regulated by steroid hormones. During postnatal development, GHOGP appears in the epithelium of the oviduct between 9 and 10 days after birth (Abe and Oikawa, 1990b). This study also suggested a relationship between the morphological differentiation of secretory cells and the appearance of the GHOGP in the secretory cells of the oviduct of newborn golden hamsters. In prepubertal female golden hamsters, a significant increase in FSH occurred in serum between 7 and 12 days after birth (Vomachka and Greenwald, 1979) and the binding of this gonadotrophin was first detected in the granulosa cells of small preantral follicles at 10 days after birth (Shaha and Greenwald, 1983). These studies suggest that the production of steroid hormones by the ovary occurs approximately at 10 days after birth, and provide the basis for the hypothesis that the biosynthesis of GHOGP is initiated by ovarian steroid hormones in the oviductal epithelium of golden hamsters during postnatal development.

Study of the influence of hormones on the initiation of GHOGP biosynthesis in the oviduct of the newborn golden hamster is important for clarifying the physiological function of this glycoprotein and the functional maturation of the oviduct. The present study was designed to investigate the hormonal control of GHOGP production in the epithelial cells of the oviduct in newborn golden hamsters. An immunohistochemical examination was undertaken to determine the effects of oestradiol and progesterone on the appearance of GHOGP in the oviducts of hormone-injected newborn golden hamsters and in the oviducts of neonates cultured in chemically defined medium in vitro.

\section{Materials and Methods}

\section{Animals and hormone treatments}

Golden hamsters (Mesocricetus auratus) were supplied with water and a commercial diet ad libitum. They were maintained at $23 \pm 22^{\circ} \mathrm{C}$ and a relative humidity of $50-60 \%$, with a controlled light cycle of $12 \mathrm{~h}$ of fluorescent light per day.

Oestradiol (Sigma Chemicals, St Louis, MO) and progesterone (Nakarai Chemicals, Kyoto) were dissolved in sesame oil and stored at $-20^{\circ} \mathrm{C}$. The 1.5-day-old female golden hamsters were injected daily with oestradiol or progesterone at $12: 00 \mathrm{~h}$ each day. The injection volume was $0.01 \mathrm{ml}$ per hamster for each hormone; i.p. injections were administered from the dorsal side. Control hamsters were injected with sesame oil alone in the same manner. Animals were killed by cervical dislocation $24 \mathrm{~h}$ after the last injection and their oviducts were excised.

\section{Monoclonal antibody}

In all immunolabelling experiments, culture supernatants that contained $\mathrm{mAb} C 11 E 8$, raised against materials obtained from the golden hamster oviduct (Abe et al., 1992), were used for the detection of GHOGP. The characterization of $\mathrm{mAb}$ C11E8 was described by Abe et al. (1992). In western blotting analysis, $\mathrm{mAb}$ C11E8 bound specifically to a broad band that corresponded to macromolecules of $>200 \mathrm{kDa}$ in oviductal extracts of the golden hamster that had been subjected to SDS-PAGE under reducing conditions. During indirect enzyme immunostaining, $\mathrm{mAb}$ C11B8 reacted with epithelial cells of the oviduct and, to a lesser extent, with some other tissues of the golden hamster. mAb C11E8 reacted selectively with the zona pellucida of oviductal eggs of golden hamsters but not with that of ovarian eggs.

\section{Electrophoresis and immunoblotting}

The biochemical characteristics of antigens that crossreacted with the mAb C11E8 were determined by immunoblotting. Tissues were homogenized on ice with a glass homogenizer in PBS ( $\mathrm{pH}$ 7.4) that contained $1 \mathrm{mmol}$ phenylmethylsulfonyl fluoride $\mathrm{l}^{-1}$ (PMSF; Sigma). The suspensions were centrifuged at $20000 \mathrm{~g}$ for $20 \mathrm{~min}$. Aliquots of the resulting supernatants, containing 5-10 $\mu \mathrm{g}$ protein, were separated by SDS-PAGE (Laemmli, 1970) on gradient gels (3-15\% polyacrylamide) and were transferred to nitrocellulose membranes. The membranes (blots) were washed in PBS and incubated in $3 \%(w / v)$ BSA in PBS at $37^{\circ} \mathrm{C}$ for $1 \mathrm{~h}$ or at $4^{\circ} \mathrm{C}$ overnight. The blots were then incubated with the culture supernatant that contained the $\mathrm{mAb}$ (concentration of IgG, $60 \mu \mathrm{g} \mathrm{ml}^{-1}$ ) as the primary antibody for $\mathrm{I}-2 \mathrm{~h}$ at room temperature and washed in PBS. After the washing step, the second antibody, horseradish peroxidase (HRP)-conjugated antibodies raised in rabbit against mouse immunoglobulin (DAKOPATTS, Glostrup), diluted 1:500 in PBS, was allowed to react with the blots for $I \mathrm{~h}$ at room temperature. After washing in PBS, the blots were incubated with the colour-development solution, Tris- $\mathrm{HCl}$ buffer $(\mathrm{pH} 7.2)$ that contained $0.5 \%(\mathrm{w} / \mathrm{v})$ diaminobenzidine (DAB) and $0.025 \% \mathrm{H}_{2} \mathrm{O}_{2}$. The blots were then washed in water and air-dried.

\section{Immunohistochemical staining}

Oviducts were fixed in 10\% formalin in distilled water. The specimens were embedded in paraffin wax and cut at $5 \mu \mathrm{m}$ thickness. Immunohistochemical staining was performed by the methods described by Abe and Oikawa (1990b, 1991). Deparaffinized and rehydrated sections were treated with $1 \% \mathrm{H}_{2} \mathrm{O}_{2}$ in methanol for $10 \mathrm{~min}$ at room temperature to eliminate the endogenous peroxidase activity. After they had been washed in distilled water and PBS, the sections were treated with $3 \%$ $\mathrm{BSA}$ in PBS for $30 \mathrm{~min}$ at $37^{\circ} \mathrm{C}$ to reduce the extent of nonspecific binding of the primary antibody. The sections were then incubated with $\mathrm{mAb}$ C11E8 as the primary antibody for $\mathrm{l}-2 \mathrm{~h}$ at room temperature. After they had been washed in PBS (three times, $5 \mathrm{~min}$ each), the sections were incubated with HRP-conjugated antibodies raised in rabbit against mouse immunoglobulin, which had been diluted 1:50 in PBS, as the second antibody. The sections were then washed with PBS and incubated with the DAB containing colour-development solution for $10 \mathrm{~min}$ at room temperature. The colour reaction was stopped by washing the sections with PBS. After the development of colour, the sections were washed thoroughly in water, 
A B C D

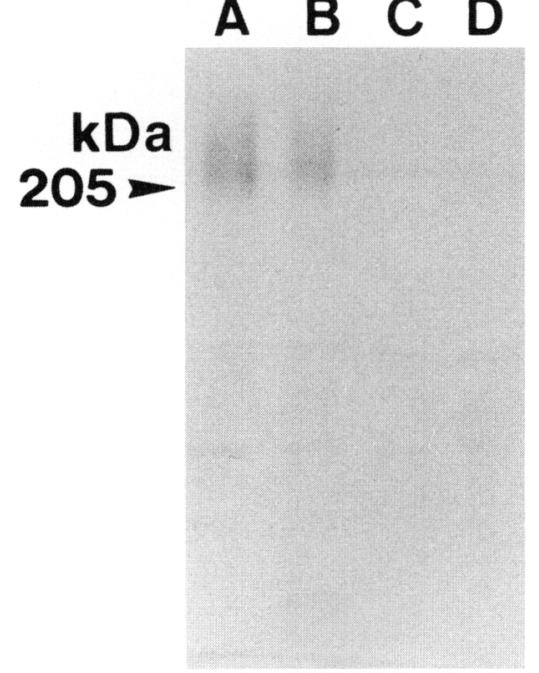

Fig. 1. Immunoblots of golden hamster oviductal extracts after fractionation by SDS-PAGE under reducing conditions and immunostaining with $\mathrm{mAb} C 11 \mathrm{E} 8$. Lane $\mathrm{A}$ : extract from an adult oviduct. Lanes B-D: extracts from oviducts after four consecutive daily treatments with oestradiol (lane B), progesterone (lane $\mathrm{C}$ ), or vehicle (lane D).

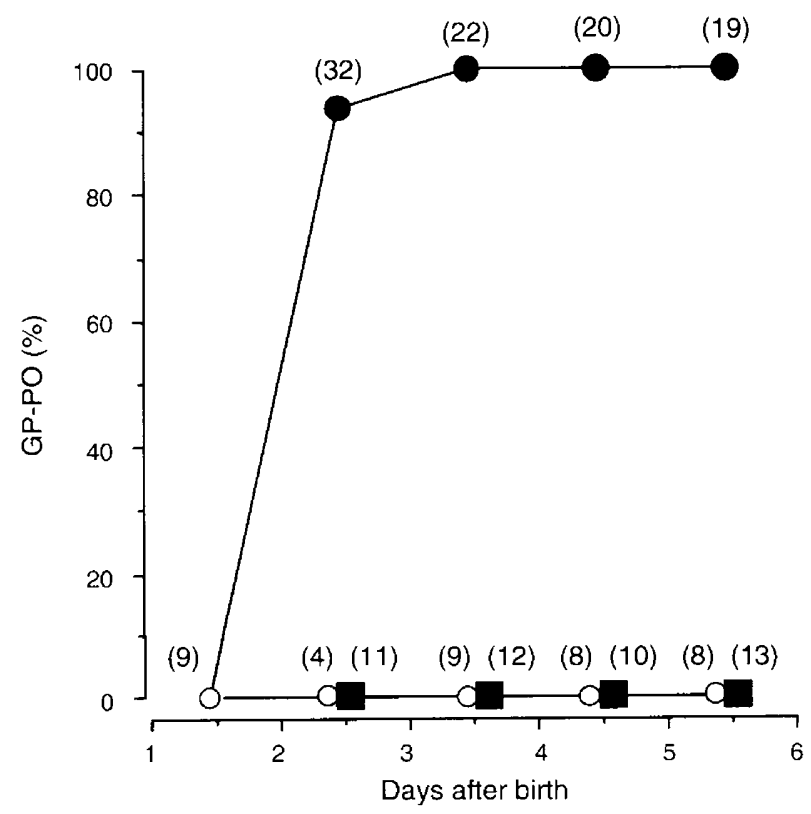

Fig. 2. The percentages of oviduct-specific glycoprotein-producing oviducts (GP-PO) in golden hamsters subjected to consecutive daily treatments with $1 \mu \mathrm{g}$ oestradiol $(\mathbf{O}), 10 \mu \mathrm{g}$ progesterone $(\boldsymbol{\square})$, or vehicle (O). The numbers in parentheses represent the numbers of oviducts examined.

counterstained with $1 \%(w / v)$ methyl green and mounted in Canada balsam for examination under a light microscope $(\mathrm{BH} 2$; Olympus Optical Co., Ltd, Tokyo).

\section{Controls for immunolabelling}

In control experiments, sections or blots were incubated with the supernatant from a culture of the myeloma cells that

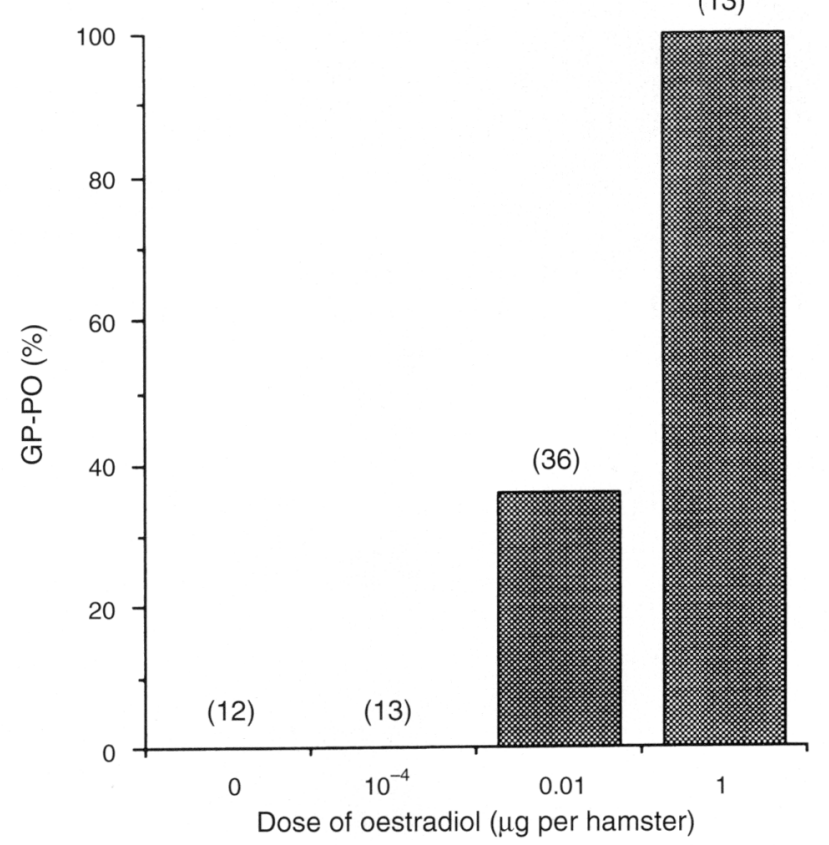

Fig. 3. The percentage of oviduct-specific glycoprotein-producing oviducts (GP-PO) in golden hamsters after two consecutive daily treatments with oestradiol at various doses. The numbers in parentheses represent the numbers of oviducts examined.

had been used for the preparation of the hybridomas or with a $\mathrm{mAb}$ directed against a surface antigen of sea urchin spermatozoa (an IgG that had been prepared in our laboratory by the same method as that used to prepare $M A b$ C11E8) instead of the supernatant that contained mAb CI1E8.

\section{Organ culture of oviducts}

Oviducts were excised from 1.5-day-old female golden hamsters under sterile conditions. The oviducts were dissected from the uterus and ovary, and they were trimmed to remove the fat and connective tissue under a stereoscopic microscope. The tissues were rinsed twice with $\mathrm{Ca}^{2+}$ - and $\mathrm{Mg}^{2+}$-free PBS and transverse segments of the oviducts, of approximately $2 \mathrm{~mm}$ length, were cut from the ampullary to the isthmic region. The segments of oviducts were distributed in the wells of a 24-well microplate (Nunc, Roskilde) and were cultured in TCM-199 (Nissui Pharmaceutical Co., Tokyo) at $37^{\circ} \mathrm{C}$ in a humidified atmosphere of $95 \%$ air: $5 \% \mathrm{CO}_{2}$ for 2 days. The oviducts were incubated in TCM-199 plus oestradiol, progesterone, or a solvent control $(0.1 \%$ ethanol). After the incubation, the oviducts were fixed in $10 \%$ formalin in distilled water, embedded in paraffin wax, and cut at $5 \mu \mathrm{m}$ thickness. The sections were subjected to immunohistochemical staining as described above.

\section{Results}

Proteins with a broad range of molecular masses above $200 \mathrm{kDa}$ in the oviductal extract obtained from golden 

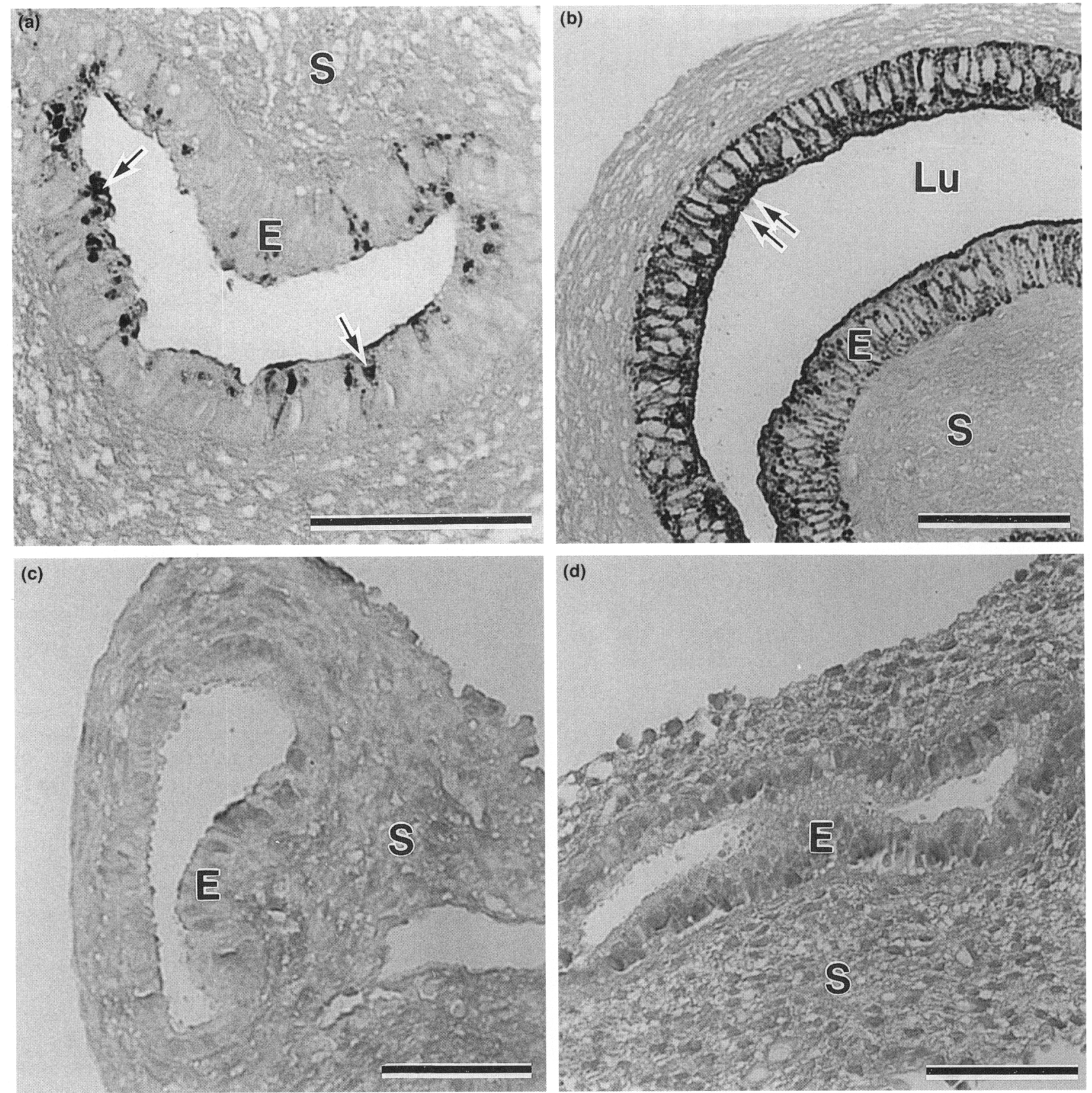

Fig. 4. Immunostaining with mAb C11E8 of sections of oviducts from golden hamsters that had been subjected to consecutive daily treatments with $1 \mu \mathrm{g}$ oestradiol $(\mathrm{a}, \mathrm{b}), 10 \mu \mathrm{g}$ progesterone (c), or vehicle (d). (a) Immunoreactive materials (arrows) appeared in the oviductal epithelium (E) after I day of treatment with oestradiol. (b) Hypertrophy of the epithelial cells was observed and large amounts of immunoreactive material filled the supranuclear cytoplasm (double arrows) in the oviduct after 4 days of treatment with oestradiol. Immunostaining with mAb C11E8 was negative in the oviductal epithelium after 4 days of treatment with progesterone (c) or with vehicle (d). Lu, lumen; S, stroma. Scale bars represent $50 \mu \mathrm{m}$.

hamsters after 4 days of consecutive daily treatments with $1 \mu \mathrm{g}$ oestradiol were stained by mAb C11E8 (Fig. 1, lane 2). This band showed the same pattern of migration as crossreactive materials in an extract of adult oviducts (Fig. 1, lane 1). No reactivity with $\mathrm{mAb}$ C11E8 was observed with oviductal extract from golden hamsters after 4 days of consecutive injections of $10 \mu \mathrm{g}$ of progesterone (Fig. 1, lane 3) or in an extract from control animals (Fig. 1, lane 4).
A large number of oviducts of different golden hamsters were fixed after consecutive daily treatments with oestradiol $(1 \mu \mathrm{g})$, progesterone $(10 \mu \mathrm{g})$, or vehicle (control). They were immunostained with $\mathrm{mAb} C 11 \mathrm{E} 8$ and examined for the presence of immunoreactive GHOGP from the ampulla to the isthmus under a light microscope. If even a faint reaction was found in the epithelium of a given oviduct, it was judged to be a glycoprotein-producing oviduct (GP-PO). The percentages of 
Table 1. Effects of oestradiol and progesterone on the production of oviduct-specific glycoprotein in the oviducts of newborn golden hamsters cultured in chemically defined medium in vitro

Number of GP-PO/

Hormone
Concentration (ng ml ${ }^{-1}$ ) number of oviducts examined

$(\%)$

$\begin{array}{lccc}\text { Control } & - & 0 / 12(0) \\ \text { Oestradiol } & 1 \times 10^{-4} & 0 / 9 & (0) \\ & 0.01 & 15 / 16 & (94.0) \\ & 1 & 9 / 10(90.0) \\ \text { Progesterone } & 100 & 9 / 11(81.8) \\ & 100 & 0 / 10(0) \\ & 1 \times 10^{-4} & 0 / 9 & (0)\end{array}$

GP-PO, glycoprotein-producing oviduct, in which immunostaining with $\mathrm{mAb}$ C11E8 was recognized.

oviducts that were judged to be GP-PO at various times after the start of hormone treatments are shown (Fig. 2). On day 1 of treatment with oestradiol, most oviducts ( $94 \%$ ) were judged to be GP-PO. After two consecutive daily treatments with oestradiol, GHOGP was detected in the epithelium of all oviducts examined. In contrast, materials reacting with $\mathrm{mAb}$ C11E8 were never detected in the epithelium of oviducts from animals subjected to four consecutive daily treatments with progesterone or from control animals.

The golden hamsters were injected with oestradiol at various doses $(0.1 \mathrm{ng}, 10 \mathrm{ng}$, and $1 \mu \mathrm{g}$ ) after two consecutive daily treatments and the percentages of GP-PO were determined by immunohistochemical staining (Fig. 3). Treatment with oestradiol increased the percentage of GP-PO in a dose-dependent manner.

The presence of materials that reacted with $\mathrm{mAb}$ CIIE8 in the oviductal epithelium at various times after the start of consecutive daily treatments with oestradiol ( $1 \mu \mathrm{g}$ ) or progesterone $(10 \mu \mathrm{g})$ are shown (Fig. 4$)$. After two consecutive daily treatments with oestradiol, the immunohistochemical reaction was observed in the oviductal epithelium, in particular, in the apical region and the Golgi area of the epithelial cells (Fig. 4a). After four consecutive daily treatments with oestradiol, most of the epithelial cells became hypertrophied and their supranuclear cytoplasm was abundant with mAb C11E8-reactive materials (Fig. $4 \mathrm{~b}$ ). In contrast, the oviducts from progesteronetreated or control animals did not react with $\mathrm{mAb}$ C1IE8 and the hypertrophy of epithelial cells was not observed (Fig. 4c, d).

Oviducts from 1.5-day-old hamsters were cultured in chemically defined medium supplemented with oestradiol or progesterone at various concentrations for 2 days and the oviducts were subjected to immunohistochemical staining to examine the effect of oestradiol and progesterone on the appearance of GHOGP in the oviduct in vitro. The numbers and percentages of oviducts that reacted with $\mathrm{mAb}$ CIIE8 are shown (Table I). A large number of GP-PO were observed in many segments of oviducts in vitro in the presence of oestradiol. No reaction was detected in segments of oviducts in the presence of progesterone or in control medium.
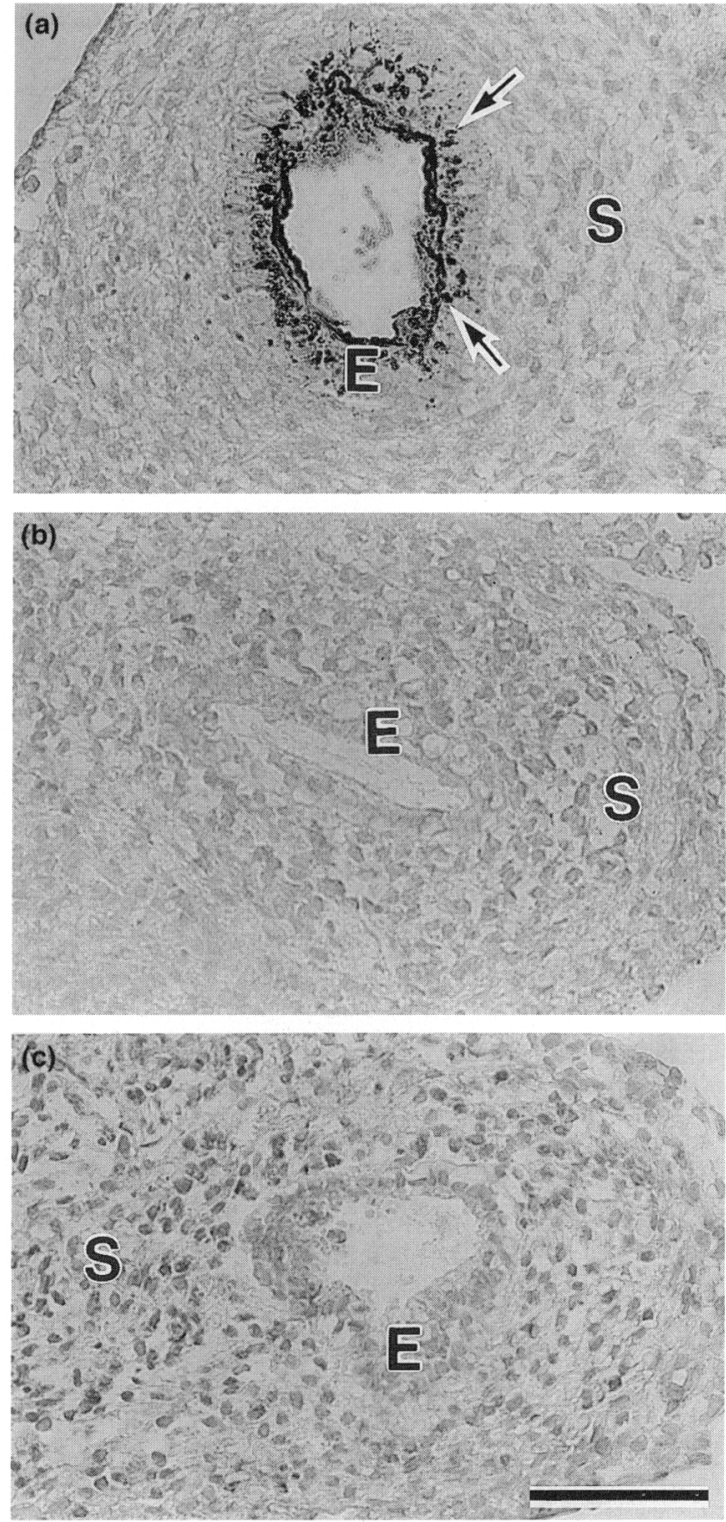

Fig. 5. Immunostaining with mAb C11E8 of sections of oviducts from 1.5-day-old golden hamsters after culture in medium containing $100 \mathrm{ng}$ oestradiol $\mathrm{ml}^{-1}$ (a) or $100 \mathrm{ng}$ progesterone $\mathrm{ml}^{-1}$ (b), or in control medium (c) for 2 days. (a) Immunoreactive material (arrows) was visible in the supranuclear cytoplasm of epithelial cells (E) of oviducts that had been cultured in oestradiol-containing medium. No immunohistochemical staining was observed in oviducts that had been cultured in medium that contained progesterone (b) or in control medium (c). S, stroma. Scale bar represents $50 \mu \mathrm{m}$.

The presence of materials that reacted with $\mathrm{mAb}$ CIIE8 in the epithelium of oviducts when they were cultured in oestradiol (100 $\mathrm{ng} \mathrm{ml}^{-1}$ ) or progesterone (100 $\mathrm{ng} \mathrm{ml}^{-1}$ ) for 2 days are shown (Fig. 5). The reactive materials were detected in the apical region and supranuclear cytoplasm of epithelial cells, as they were in the oviducts of oestradiolinjected neonatal hamsters in vivo (Fig. 5a). The oviducts cultured in the presence of progesterone or in the control medium indicated no crossreactivity with MAb CIIE8 (Fig. 5b, c). 
No specific reaction was observed in any sections or on any blots with the mAb directed against a surface antigen of sea urchin spermatozoa or with the supernatant from myeloma cell cultures (data not shown).

\section{Discussion}

Mammalian oviducts synthesize and secrete specific glycoproteins. The rates of biosynthesis of these OGPs fluctuate during the oestrous cycle and seem likely to be regulated by steroid hormones in many mammalian species, including pigs (Buhi et al., 1992), sheep (Murray, 1992, 1993), cows (Boice et al., 1990b; Abe et al., 1993; Sendai et al., 1994), primates (Fazleabas and Verhage, 1986; Verhage et al., 1989) and humans (Verhage et al., 1988). In most species, the rate of OGP synthesis is oestradiol-dependent. However, the previous results were obtained from studies with mature animals, and limited information is available about any possible correlation between oestradiol and the onset of the biosynthesis of GHOGP during ontogeny. The results of the present study revealed that exogenous oestradiol induces the appearance of GHOGP in epithelial cells of the oviduct of newborn golden hamsters. In addition, a recent indirect immunofluorescence study demonstrated that the production of a GHOGP, oviductin, which is similar to the glycoprotein investigated in the present study, was induced in oestradiol-treated prepubertal animals (Malette et al., 1995b). These findings strongly suggest that oestradiol is of primary importance for the production of GHOGPs by secretory cells of the oviduct during postnatal development in golden hamsters, although it remains to be determined whether the initiation of GHOGP production, which normally occurs in oviducts of newborn golden hamsters in vivo, is induced in an oestrogen-dependent manner.

A previous study demonstrated that the marked morphological differentiation of oviductal epithelial cells and of secretory cells, in particular, occurred approximately 10 days after birth (Abe and Oikawa, 1989). Subsequently, it was shown that GHOGP can be detected in the Golgi apparatus and secretory granules of these developing secretory cells at the same time, suggesting a coincidence between the morphological differentiation of secretory cells and the initiation of the biosynthesis of GHOGP in the golden hamster oviduct during postnatal development (Abe and Oikawa, 1990b). Exogenous oestradiol induces the morphological differentiation of secretory cells in the oviducts of newborn golden hamsters (Abe and Oikawa, 1993). Oestradiol also induces various ultrastructural changes, such as the development of Golgi apparatus and rough endoplasmic reticulum and the appearance of secretory granules, indicative of the differentiation to secretory cells, in undifferentiated epithelial cells. The present study demonstrates that injection of oestradiol induces the appearance of GHOGP in the Golgi area of undifferentiated epithelial cells in oviducts of neonatal golden hamsters. The results strongly suggest that there is a correlation between the beginning of cytodifferentiation and the onset of production of GHOGP in the oviductal secretory cells of newborn golden hamsters.

In organ culture, oestradiol also induced the appearance of GHOGP in the epithelial cells of oviducts cultured in the chemically defined medium, as occurred in vivo in oviducts of oestradiol-injected golden hamsters. Thus, it appears that oestradiol acts directly on the oviduct, although it is unclear whether the epithelial (secretory) cells of the oviduct are the direct target of oestradiol. It is well known that the actions of steroid hormones are mediated by their intracellular receptors. However, previous studies have suggested that intercellular mediators must also be involved in the actions of steroid hormones in the reproductive organs (Cunha et al., 1985; Brenner et al., 1990). In particular, it has been suggested that some hormonal effects of sex steroids on the epithelium are mediated indirectly, through the stroma, in the oviduct of the rhesus monkey (Brenner et al., 1990). The inducible mechanisms of oestradiol on the biosynthesis of GHOGP in the secretory cells of the golden hamster oviduct require further analysis, such as an investigation of putative receptors for oestradiol in the oviductal epithelium.

The biological functions of OGPs have been studied in many species (King et al., 1994; Abe et al., 1995b; Gandolfi, 1995; O'Day-Bowman et al., 1996; Hill et al., 1997; Schmidt et al., 1997; Vansteenbrugge et al., 1997). It has been suggested that a GHOGP (oviductin) may influence the penetration of spermatozoa (Boatman and Magnoni, 1995) or the interaction between spermatozoa and the zona pellucida (Kimura et al., 1994) during fertilization in vitro. However, the critical biological functions of GHOGPs in vivo remain unclear. The production of GHOGP in the oviduct of sexually mature animals has not yet been shown to be oestrogen-dependent, and strong immunohistochemical staining by mAb C1IE8 has been observed in the epithelium of the oviduct of adult golden hamsters throughout the oestrous cycle $(\mathrm{H}$. Abe and $\mathrm{H}$. Hoshi, unpublished). Ovarian steroid hormones control the functional state of the epithelium of the mammalian oviduct, for example the secretory activity (Brenner and Maslar, 1988). If the exact functional role of GHOGP in reproductive events are to be determined, the influences of various hormones on the biosynthesis of GHOGP in the epithelial cells of the oviduct need to be investigated in detail.

The authors thank $Y$. Sendai for supplying the monoclonal antibody against a sea urchin protein. This work was supported in part by a grant from Research Fund of the Bio-Oriented Technology Research Advancement (BRAIN) of Japan.

\section{References}

Abe $\mathrm{H}$ and Oikawa $\mathrm{T}$ (1989) Differentiation of the golden hamster oviduct epithelial cells during postnatal development: an electron microscopic study Journal of Experimental Zoology 252 43-52

Abe $\mathbf{H}$ and Oikawa $\mathrm{T}$ (1990a) Ultrastructural evidence for an association between an oviductal glycoprotein and the zona pellucida of the golden hamster egg Journal of Experimental Zoology 256 210-221

Abe $\mathrm{H}$ and Oikawa T (1990b) Study of the differentiation of secretory cells in the golden hamster oviductal epithelium by use of a monoclonal antibody Journal of Experimental Zoology 254 97-106

Abe $\mathrm{H}$ and Oikawa $\mathrm{T}$ (1991) Immunocytochemical localization of an oviductal zona pellucida glycoprotein in the oviductal epithelium of the golden hamster Anatomical Record 229 305-314

Abe $\mathrm{H}$ and Oikawa $\mathrm{T}$ (1993) Effects of estradiol and progesterone on the cytodifferentiation of epithelial cells in the newborn golden hamster Anatomical Record 235 390-398

Abe H, Ookata K, Abe M and Oikawa T (1992) Immunological characterization of oviductal glycoproteins associated with the zona pellucida of the golden hamster egg Journal of Experimental Zoology 262 209-218 
Abe H, Numazawa C, Abe M, Onodera M and Katsumi A (1993) Immunocytochemical localization of oviduct-specific glycoproteins in the bovine oviductal epithelium at follicular and luteal phases Cell and Tissue Research $\mathbf{2 7 4}$ $41-47$

Abe H, Onodera M and Sugawara S (1995a) Immunological detection and characterization of an estrus-associated antigen in the goat oviduct journal of Experimental Zoology 272 134-141

Abe H, Sendai Y, Satoh T, and Hoshi H (1995b) Bovine oviduct-specific glycoprotein is a potent factor for the maintenance of the viability and motility of bovine spermatozoa in vitro. Molecular Reproduction and Development 42 226-232

Boatman DE and Magnoni GE (1995) Identification of a sperm penetration factor in the oviduct of the golden hamster Biology of Reproduction 52 199-207

Boice ML, McCarthy TJ, Mavrogianis PA, Fazleabas AT and Verhage HG (1990a) Localization of oviductal glycoproteins within the zona pellucida and perivitelline space of ovulated ova and early embryos in baboon (Papio anubis) Biology of Reproduction 43 340-346

Boice ML, Geisert RD, Blair RM and Verhage HG (1990b) Identification and characterization of bovine oviductal glycoproteins synthesized at estrus Biology of Reproduction 43 457-465

Boice ML, Mavrogianis PA, Murphy CN, Prather RS and Day BN (1992) Immunocytochemical analysis of the association of bovine oviduct-specific glycoproteins with early embryos Journal of Experimental Zoology 263 225-229

Brenner RM and Maslar I (1988) The primate oviduct and endometrium. In The Physiology of Reproduction pp 303-329 Eds E Knobil and JD Neill. Raven Press, New York

Brenner RM, West NB and McClellan MC (1990) Estrogen and progestin receptors in the reproductive tract of male and female primates Biology of Reproduction 42 II-19

Buhi WC, Ashworth CJ, Bazer FW and Alvarez IM (1992) In vitro synthesis of oviductal secretory proteins by estrogen-treated ovariectomized gilts Journal of Experimental Zoology 262 426-435

Buhi WC, O'Brien B, Alvarez IM, Erdos G and Dubois D (1993) Immunogold localization of porcine oviductal secretory proteins within the zona pellucida, perivitelline space, and plasma membrane of oviductal and uterine oocytes and early embryos Biology of Reproduction 48 1274-1283

Cunha GR, Bigsby RM, Cooke PS and Sugimura Y (1985) Stromal-epithelial interactions in adult organs Cell Differentiation 17 137-148

Fazleabas AT and Verhage HG (1986) The detection of oviduct-specific proteins in the baboon (Papio anubis) Biology of Reproduction 35 455-462

Gandolfi F (1995) Functions of proteins secreted by oviduct epithelial cells Microscopy Research and Technique 32 1-12

Hill JL, Wade MG, Nancarrow CD, Kelleher DL and Boland MP (1997) Influence of ovine oviducal amino acid concentrations and an ovine oestrus-associated glycoprotein on development and viability of bovine embryos Molecular Reproduction and Development 47 4164-169

Hunter RHF (1994) Modulation of gamete and embryonic microenvironments by oviduct glycoproteins Molecular Reproduction and Development 39 176-181

Kapur RP and Johnson LV (1985) An oviductal fluid glycoprotein associated with ovulated mouse ova and early embryos Developmental Biology 112 $89-93$

Kimura H, Matsuda J, Ogura A, Asano T and Naiki M (1994) Affinity binding of hamster oviductin to spermatozoa and its influence on in vitro fertilization Molecular Reproduction and Development 39 322-327

King RS, Anderson SH and Killian GJ (1994) Effect of bovine oviductal estrus-associated protein on the ability of sperm to capacitate and fertilize oocytes Journal of Andrology 15 468-478
Laemmli UK (1970) Cleavage of structural proteins during the assembly of the head of bacteriophage T4 Nature 227 680-685

Leveille MC, Roberts KD, Chevalier S, Chapdelaine A and Bleau G (1987) Uptake of an oviductal antigen by the hamster zona pellucida Biology of Reproduction $36227-238$

McNutt T, Rogowski L, Vasilatos-Younken R and Killian G (1992) Adsorption of oviductal fluid proteins by the bovine sperm membrane during in vitro capacitation Molecular Reproduction and Development 33 313-323

Malette B, Paquette Y, Merlen Y and Bleau G (1995a) Oviductins possess chitinase- and mucin-like domains: a lead in the search for the biological function of these oviduct-specific ZP-associating glycoproteins Molecular Reproduction and Development $41384-397$

Malette B, Filion B, St-Jacques S, Kan FWK and Bleau G (1995b) Hormonal control of the biosynthesis of hamster oviductin Microscopy Research and Technique 31 470-477

Murray MK (1992) Biosynthesis and immunocytochemical localization of an estrogen-dependent glycoprotein and associated morphological alterations in the sheep ampulla oviduct Biology of Reproduction 47 889-902

Murray MK (1993) An estrogen-dependent glycoprotein is synthesized and released from the oviduct in a temporal- and region-specific manner during early pregnancy in the ewe Biology of Reproduction $\mathbf{4 8} 446-453$

O'Day-Bowman MB, Mavrogianis PA, Reuter LM, Johnson DE, Fazleabas AT and Verhage HG (1996) Association of oviduct-specific glycoproteins with human and baboon (Papio anubis) ovarian oocytes and enhancement of human sperm binding to human hemizonae following in vitro incubation Biology of Reproduction 54 60-69

Oikawa T, Sendai Y, Kurata S and Yanagimachi R (1988) A glycoprotein of oviductal origin alters biochemical properties of the zona pellucida of hamster egg Gamete Research 19 113-122

Satoh T, Abe H, Sendai Y, Iwata H and Hoshi H (1995) Biochemical characterization of a bovine oviduct-specific sialo-glycoprotein that sustains sperm viability in vitro. Biochimica et Biophysica Acta 1266 117-123

Schmidt A, Mavrogianis PA, O'Day-Bowman MB and Verhage HG (1997) Species-specific effect of oviductal glycoproteins on hamster sperm binding to hamster oocytes Molecular Reproduction and Development 46 201-207

Sendai Y, Abe H, Kikuchi M, Satoh T and Hoshi H (1994) Purification and molecular cloning of bovine oviduct-specific glycoprotein Biology of Reproduction 50 927-934

Shaha C and Greenwald GS (1983) Development of steroidgenic activity in the ovary of the prepubertal hamster. I. Response to in vivo or in vitro exposure to gonadotropins Biology of Reproduction 28 1231-1241

Sutton R, Wallace ALC, Engel H and Nancarrow CD (1984) Binding of sheep oviducal fluid proteins to spermatozoa. In Reproduction in Sheep PP 140-143 Eds DR Lindsay and DT Pearce. Australian Academy of Science, Canberra

Vansteenbrugge A, van Langendonckt A, Massip A and Dessy F (1997) Effect of estrus-associated glycoprotein and tissue inhibitor of metalloproteinase- 1 secreted by oviduct cells on in vitro bovine embryo development Molecular Reproduction and Development 46 527-534

Verhage HG, Fazleabas AT and Donnelly K (1988) The in vitro synthesis and release of proteins by the human oviduct Endocrinology 122 1639-1645

Verhage HG, Boice ML, Mavrogianis P, Donnelly K and Fazleabas AT (1989) Immunological characterization and immunocytochemical localization of oviduct-specific glycoproteins in the baboon (Papio anubis) Endocrinology 124 2464-2472

Vomachka AJ and Greenwald GS (1979) The development of gonadotropin and steroid hormone patterns in male and female hamsters from birth to puberty Endocrinology 105 960-966 